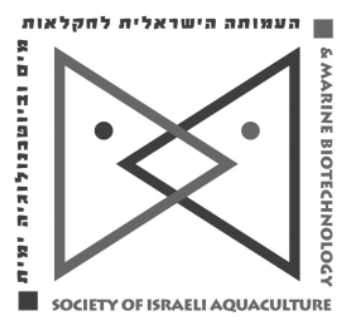

The IJA appears exclusively as a peer-reviewed on-line open-access journal at http://www.siamb.org.il/. To read papers free of charge, please register online at registration form.

Sale of IJA papers is strictly forbidden.

\title{
Stenotrophomonas maltophilia: an Emerging Pathogen of Ascites Disease in Farmed Yellow Catfish Pelteobagrus fulvidraco
}

\author{
Haipeng Cao ${ }^{1,2,3}$, Cheng Guo 1,2,3, Jian An ${ }^{4}$ Liqun Lu, 1,2,3, Xianle \\ Yang ${ }^{1,2,3}$, Yibin Yang ${ }^{5 *}$ \\ The first two authors contributed to equal work.
}

${ }^{1}$ National Pathogen Collection Center for Aquatic Animals, Shanghai Ocean University, Shanghai 201306, P.R. China.

2 Shanghai Collaborative Innovation for Aquatic Animal Genetics and Breeding, Shanghai Ocean University, Shanghai 201306, P.R. China. ${ }^{3}$ Shanghai Engineering Research Center of Aquaculture, Shanghai Ocean University, Shanghai 201306, P.R. China.

${ }^{4}$ Lianyungang Marine and Fisheries Development Promotion Center, Lianyungang 222000, P.R. China

Keywords: : Stenotrophomonas maltophilia; Pelteobagrus fulvidraco; pathogen; ascites disease

\begin{abstract}
Ascites disease causes significant economic losses in yellow catfish Pelteobagrus fulvidraco. Yet only scare information is reported on Stenotrophomonas maltophilia as a pathogen for yellow catfish. In this study, a virulent strain, temporarily named WY1, was isolated from diseased yellow catfish fry suffering from ascites disease, identified phenotypically and molecularly as $S$. maltophilia. A phylogenetic tree was constructed to examine isolate WY1 and compare it to other known isolates. In addition, isolate WY1 is apparently susceptible to aminoglycosides and tetracycline drugs for veterinary uses in aquaculture as revealed when screened against a range of common antibiotics. To the best of our knowledge, this is the first report of $S$. maltophilia as a pathogen of ascites disease in farmed yellow catfish.
\end{abstract}

\footnotetext{
* Corresponding author. Tel: +862781780223; Fax: +862781780223; Email: yang19890923@yeah.net
} 


\section{Introduction}

Yellow catfish Pelteobagrus fulvidraco is a commercially important freshwater fish widely cultivated in China, Japan, Korea, and Southeast Asian countries (Li, 2000). In China, the yellow catfish industry has grown rapidly and is very profitable. In 2016, the total output reached over 417,000 tons (Ministry of Agriculture of China, 2017). However, under intensive culture, this industry has been seriously affected by bacterial diseases (Zhang et al., 2009; Yang et al., 2017). Hence, more attention should be paid to bacteriosis in general, to enable further sustainable development of this industry.

Ascites is one of the most important infectious bacterial diseases in a wide range of fish including yellow catfish (Zhang et al., 2014). This disease resulted in significant economic losses in Ayu Plecoglossus altivelis (Nishimori et al., 2000), channel catfish Ictalurus punctatus (Wei et al., 2014), Japanese flounder Paralichthys olivaceus (Zhu et al., 2006), mandarin fish Siniperca chuatsi (Cao et al., 2013) and turbot Scophthalmus maximus (Li et al., 2006). Studies have shown that ascites disease in fish can be the result of several bacterial pathogens such as Aeromonas hydrophila (Liang et al., 2012), Aeromonas sobria (Wei et al., 2014), Pseudomonas plecoglossicida (Nishimori et al., 2000), Vibrio cholerae (Cao et al., 2013), Vibrio mimicus (Zhang et al., 2014). Until now, however, few reports have been published on Stenotrophomonas maltophilia as a causal agent of this disease.

Between April and June of 2012 to 2016, ascites, characterized by abdominal distension (Zhang et al., 2009), occurred frequently in yellow catfish cultured in regions of Chongqing, Guangdong, Guangxi, Jiangxi, and Liaoning provinces, China, particularly during the fry culture stage. This disease is highly infectious and lethal, causing $20 \%$ to $90 \%$ mortality. In the present study, we isolated and identified a S. maltophilia pathogen as a causative agent for this disease, and determined its taxonomy and antibiotic susceptibility. To our knowledge, this is the first report of $S$. maltophilia as a pathogen for farmed yellow catfish.

\section{Materials and methods}

Fish samples. Sixteen ascites-infected yellow catfish fry averaging $0.3 \pm 0.1 \mathrm{~g}$, were sampled from infected ponds of a fish farm in Foshan, Guangdong China in April 2016. The farm has six acres of ponds with yellow catfish stocked at an initial density of 250,000 fry per acre. The water quality during the disease outbreak was $\mathrm{pH} 8.50,0.20$ $\mathrm{mg} / \mathrm{L}$ total ammonia, $0.15 \mathrm{mg} / \mathrm{L}$ nitrite and $5.12 \mathrm{mg} / \mathrm{L}$ dissolved oxygen. Diseased samples were placed in sterile bags, kept in ice and transported to the laboratory.

Bacterial isolation. Each sampled diseased fish was externally disinfected with $75 \%$ alcohol and dissected. Before conducting a careful detection of parasites and viruses using traditional methods as described by Huang et al. (2010) and Ma et al. (2015), samples from livers and ascetic fluid of diseased fish were streaked onto nutrient agar (NA) (Sinopharm Chemical Reagent Co., Ltd.) with a flamed loop. After incubation for two days at $28^{\circ} \mathrm{C}$, bacteria isolated from fish were subcultured on the same media plate to check the purity of the isolate. Pure isolates of the predominant uniform colonies were stored at $-80^{\circ} \mathrm{C}$ supplemented with $15 \%$ glycerol. A representative isolate, temporarily named WY1, was characterized further in the present study.

\section{Bacterial identification}

Molecular identification. The extraction of genomic DNA from isolate WY1, as well as PCR amplification and sequencing of its 16S rRNA gene, were performed as described by Geng et al. (2010). Near complete 16S rRNA gene sequence was assembled using Editseq and Seqman in DNAstar software. A search was performed in the National Centre for Biotechnology Information (NCBI) database for sequence homology using the Basic Local Alignment Search Tool (BLAST) program. A phylogenetic tree from near-complete $16 S$ rRNA gene sequence of the isolate and its homologous sequences was constructed using the neighbor-joining method.

Phenotypic identification. Isolate WY1 was identified phenotypically using API 32E test strips as recommended by Cheng et al. (2013). The test strip was incubated at $37^{\circ} \mathrm{C}$ and observed after $24 \mathrm{~h}$ against the API identification index. The type strain ATCC51331 of S. maltophilia was used as the control. 
Bacterial virulence assay. Bacterial virulence was examined by experimentally infecting healthy cultured yellow catfish. One hundred healthy yellow catfish averaging $36.1 \pm 2.1 \mathrm{~g}$ were obtained from Baishazhou fishery Co., Ltd. in Wuhan, China. Their health status was evaluated according to the guidelines recommended by Zheng et al. (2012). The experimental fish were acclimated in ten replicate aquaria (each stocked with ten fish) supplied with $50 \mathrm{~L}$ of aerated filtered farming water at $25^{\circ} \mathrm{C}$ for 14 days. Prior to the bacterial virulence assay isolate WY1 was inoculated onto NA plate, incubated at $28^{\circ} \mathrm{C}$ for $24 \mathrm{~h}$, and washed with normal saline into a sterile tube. Its cell density was determined by counting colony forming units after a ten-fold serial dilution in sterile distilled water. Two replicates of ten healthy fish in four treatment groups were challenged by intraperitoneal injection with $0.2 \mathrm{~mL}$ of isolate WY1 at cell densities of 2.0 $\times 10^{4} \mathrm{CFU} / \mathrm{mL}, 2.0 \times 10^{5} \mathrm{CFU} / \mathrm{mL}, 2.0 \times 10^{6} \mathrm{CFU} / \mathrm{mL}$ and $2.0 \times 10^{7} \mathrm{CFU} / \mathrm{mL}$. Another two replicates of ten healthy fish exposed to the same experimental conditions and injected intraperitoneally with $0.2 \mathrm{~mL}$ of normal saline that served as control. The experimental fish were kept at $25^{\circ} \mathrm{C}$ and observed daily for seven days without feeding and water change. Any dead fish were immediately removed and sampled to confirm if the mortality was caused specifically by the challenge isolate. The mean lethal dose $\left(L_{50}\right)$ value is calculated according to the graphical probit method as recommended by Ogbuagu \& Iwuchukwu (2014).

Antibiotic sensitivity assay. The antibiotic sensitivity of isolate WY1 was assayed on NA plates using the Kirby-Bauer disk diffusion method as described by Joseph et al. (2011). Nineteen antibiotic discs were acquired from Hangzhou Tianhe Microorganism Reagent Co., Ltd. The inhibition zones were measured after a $24 \mathrm{~h}$ incubation period at $28^{\circ} \mathrm{C}$. The antibiotic susceptibility was determined according to the manufacturer's guidelines.

\section{Results}

Bacterial identification. A dominant isolate WY1 was isolated from the diseased yellow catfish fry and identified by molecular and phenotypic methods as S. maltophilia. Its near complete 16S rRNA gene sequence (1400 nucleotides) was submitted to GenBank database with the accession no. MF458998. A similarity of $99 \%$ was observed in the $16 \mathrm{~S}$ rRNA gene sequence between the WY1 isolate and other $S$. maltophilia isolates from the GenBank database. The phylogenetic tree confirms that the isolate WY1 is identified with S. maltophilia strain (Figure 1).

Figure 1. A $16 \mathrm{~S}$ rRNA gene tree of 14 known bacteria and the WY1 isolate constructed using the neighbour-joining method. The bootstrap values (\%) are shown besides the clades, accession numbers are indicated beside the names of strains, and scale bars represent distance values.

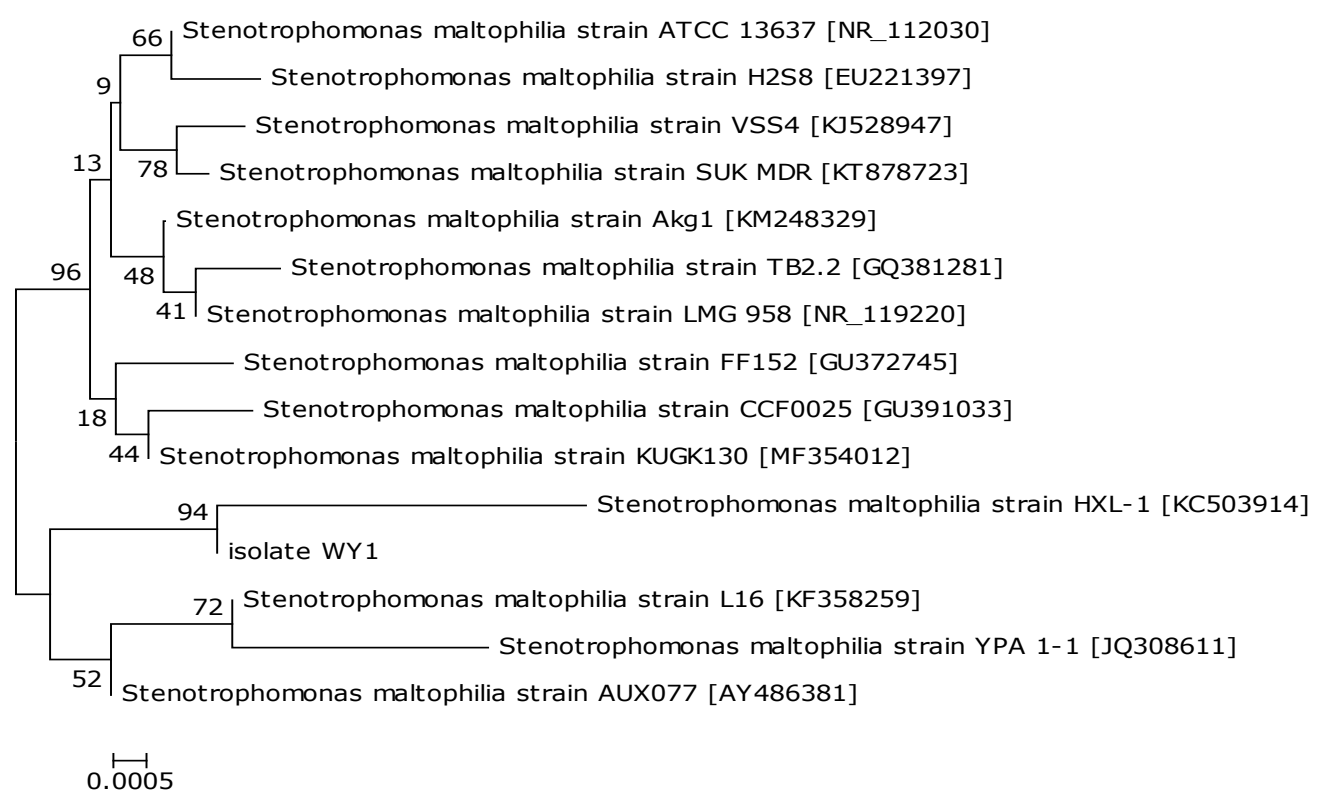


This is again confirmed by the phenotypic features as S. maltophilia (Table 1) with $96.88 \%$ identity compared to the reference strain. No parasites and viruses were detected in the diseased yellow catfish from which the isolate WY1 was obtained.

Table 1. Phenotypic characteristics of isolate WY1.

\begin{tabular}{|c|c|c|}
\hline \multirow{2}{*}{ Tests } & \multicolumn{2}{|r|}{ Reaction } \\
\hline & $W Y 1$ & ATCC51331 \\
\hline Arginine dihydrolase & $\mathrm{R}^{-}$ & $\mathrm{R}^{-}$ \\
\hline Lysine decarboxylase & $\mathrm{R}^{-}$ & $\mathrm{R}^{-}$ \\
\hline Lipase & $\mathrm{R}^{+}$ & $\mathrm{R}^{+}$ \\
\hline L-aspartate aminase & $\mathrm{R}^{-}$ & $\mathrm{R}^{-}$ \\
\hline$\underline{\mathrm{N} \text {-acetyl- } \beta \text {-glucosaminidase }}$ & $\mathrm{R}^{-}$ & $\mathrm{R}^{-}$ \\
\hline$\overline{\alpha-g a l a c t o s i d a s e}$ & $\mathrm{R}^{+}$ & $\mathrm{R}^{+}$ \\
\hline$\alpha$-glucosaccharase & $\mathrm{R}^{+}$ & $\mathrm{R}^{+}$ \\
\hline$\alpha$-maltosidase & $\mathrm{R}^{+}$ & $\mathrm{R}^{+}$ \\
\hline$\underline{\beta}$-galactosidase & $\mathrm{R}^{+}$ & $\mathrm{R}^{+}$ \\
\hline$\underline{\beta}$-glucosaccharase & $\mathrm{R}^{+}$ & $\mathrm{R}^{+}$ \\
\hline$\underline{\beta}$-glucuronidase & $\mathrm{R}^{-}$ & $\mathrm{R}^{-}$ \\
\hline Ürease & $\mathrm{R}^{-}$ & $\mathrm{R}^{-}$ \\
\hline Orinithine decarboxylase & $\mathrm{R}^{-}$ & $\mathrm{R}^{-}$ \\
\hline Indole production & $\mathrm{R}^{-}$ & $\mathrm{R}^{-}$ \\
\hline Malonate utilization & $\mathrm{R}^{-}$ & $\mathrm{R}^{+}$ \\
\hline \multicolumn{3}{|l|}{ Acid production from } \\
\hline Adonitol & $\mathrm{R}^{-}$ & $\mathrm{R}^{-}$ \\
\hline Galacturonic acid & $\mathrm{R}^{-}$ & $\mathrm{R}^{-}$ \\
\hline Inositol & $\mathrm{R}^{-}$ & $\mathrm{R}^{-}$ \\
\hline L-arabinose & $\mathrm{R}^{-}$ & $\mathrm{R}^{-}$ \\
\hline L-arabitol & $\mathrm{R}^{-}$ & $\mathrm{R}^{-}$ \\
\hline L-rhamnose & $\mathrm{R}^{-}$ & $\mathrm{R}^{-}$ \\
\hline D-arabitol & $\mathrm{R}^{-}$ & $\mathrm{R}^{-}$ \\
\hline D-cellobiose & $\mathrm{R}^{-}$ & $\mathrm{R}^{-}$ \\
\hline D-glucose & $\mathrm{R}^{-}$ & $\mathrm{R}^{-}$ \\
\hline D-maltose & $\mathrm{R}^{-}$ & $\mathrm{R}^{-}$ \\
\hline D-mannitol & $\mathrm{R}^{-}$ & $\mathrm{R}^{-}$ \\
\hline D-sorbitol & $\mathrm{R}^{-}$ & $\mathrm{R}^{-}$ \\
\hline D-sucrose & $\mathrm{R}^{-}$ & $\mathrm{R}^{-}$ \\
\hline D-trehalose & $\mathrm{R}^{-}$ & $\mathrm{R}^{-}$ \\
\hline 5-ketone-potassium gluconate & $\mathrm{R}^{-}$ & $\mathrm{R}^{-}$ \\
\hline Palatinose & $\mathrm{R}^{-}$ & $\mathrm{R}^{-}$ \\
\hline Sodium pyruvate & $\mathrm{R}^{-}$ & $\mathrm{R}^{-}$ \\
\hline
\end{tabular}

$\mathrm{R}^{+}$: positive reaction; $\mathrm{R}^{-}$: negative reaction.

Isolate WY1 was virulent to yellow catfish with a LD50 value of $1.12 \times 10^{5} \mathrm{CFU} / \mathrm{mL}$ (Table 2). The infected fish exhibited similar clinical symptoms to those seen in the originally diseased fish (Figure 2). When fish were challenged with a concentration of 2.0 $\times 10^{7} \mathrm{CFU} / \mathrm{mL}$, acute mortality was observed. The isolate WY1 could be re-isolated from experimentally dead fish. No clinical signs or mortality were noted in the control fish.

Table 2. Cumulative mortality of experimental yellow catfish infected by the isolate WY1.

\begin{tabular}{|c|c|c|c|c|c|c|c|c|c|c|c|}
\hline \multirow{2}{*}{ Group } & \multirow{2}{*}{$\begin{array}{c}\text { Concentration } \\
(C F U / m L)\end{array}$} & \multirow{2}{*}{$\begin{array}{l}\text { Fish } \\
\text { no. }\end{array}$} & \multicolumn{7}{|c|}{$\begin{array}{l}\text { Dead fish no. on day after } \\
\text { challenge }\end{array}$} & \multirow{2}{*}{$\begin{array}{c}\text { Average } \\
\text { cumulative } \\
\text { mortality (\%) }\end{array}$} & \multirow{2}{*}{$\begin{array}{l}\text { LD } D_{50} \text { value } \\
(C F U / m L)\end{array}$} \\
\hline & & & 1 & 2 & 3 & 4 & 5 & 6 & 7 & & \\
\hline \multirow{2}{*}{ Control } & \multirow[b]{2}{*}{0} & 10 & 0 & 0 & 0 & 0 & 0 & 0 & 0 & \multirow[b]{2}{*}{0} & \multirow{10}{*}{$1.12 \times 10^{5}$} \\
\hline & & 10 & 0 & 0 & 0 & 0 & 0 & 0 & 0 & & \\
\hline \multirow{2}{*}{ Treatment 1} & \multirow{2}{*}{$2.0 \times 10^{4}$} & 10 & 0 & 0 & 1 & 1 & 0 & 0 & 0 & \multirow{2}{*}{25} & \\
\hline & & 10 & 0 & 1 & 1 & 1 & 0 & 0 & 0 & & \\
\hline \multirow{2}{*}{ Treatment 2} & \multirow{2}{*}{$2.0 \times 10^{5}$} & 10 & 0 & 1 & 2 & 1 & 1 & 0 & 0 & \multirow{2}{*}{55} & \\
\hline & & 10 & 1 & 1 & 1 & 2 & 1 & 0 & 0 & & \\
\hline \multirow{2}{*}{ Treatment 3} & \multirow{2}{*}{$2.0 \times 10^{6}$} & 10 & 3 & 3 & 1 & 1 & 1 & 0 & 0 & \multirow{2}{*}{90} & \\
\hline & & 10 & 2 & 3 & 1 & 2 & 0 & 1 & 0 & & \\
\hline \multirow{2}{*}{ Treatment 4} & \multirow{2}{*}{$2.0 \times 10^{7}$} & 10 & 4 & 4 & 1 & 1 & 0 & 0 & 0 & \multirow{2}{*}{100} & \\
\hline & & 10 & 5 & 4 & 1 & 0 & 0 & 0 & 0 & & \\
\hline
\end{tabular}


Figure 2. Pathological symptoms of the diseased yellow catfish fry. A: arrow shows abdominal distension. B: arrow shows dead fry floating to the water surface.

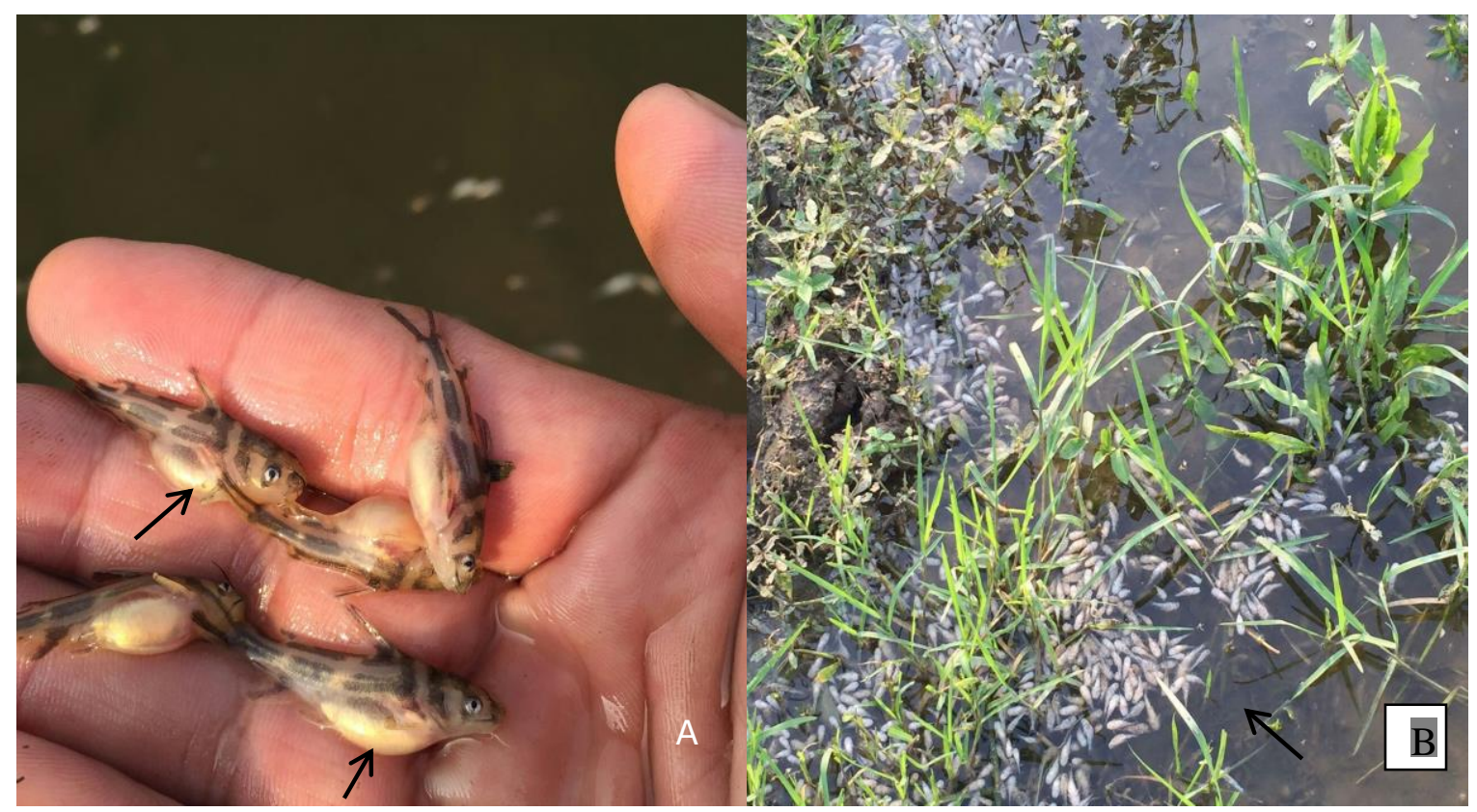

Antibiotic susceptibility. The antibiotic sensitivity of isolate WY1 is shown in Table 3. The data indicate that the isolate WY1 is sensitive to ceftazidine, cefotaxime, doxycycline, gentamycin, kanamycin, neomycin, streptomycin, tetracycline, and resistant to the macrolides, penicillin, quinolones, sulfonamides antibiotics. This suggests that the isolate WY1 has not developed resistance to aminoglycosides and tetracycline antimicrobials.

Table 3. Susceptibility of isolate WY1 to antibiotics.

\begin{tabular}{|c|c|c|}
\hline Antibiotics & $\begin{array}{l}\text { Content } \\
\text { ( } \mu \mathrm{g} / \text { disc) }\end{array}$ & Inhibition zone diameter $(\mathrm{mm})$ \\
\hline Amoxicillin & 10 & $0 \pm 0^{R}$ \\
\hline Ampicillin & 10 & $0 \pm 0^{R}$ \\
\hline Ceftazidine & 30 & $24.80 \pm 0.42^{\mathrm{S}}$ \\
\hline Cefotaxime & 30 & $29.50 \pm 0.71^{\mathrm{s}}$ \\
\hline Ciprofloxacin & 5 & $0 \pm 0^{R}$ \\
\hline Doxycycline* & 30 & $23.65 \pm 0.64^{\mathrm{S}}$ \\
\hline Enrofloxacin* & 5 & $0 \pm 0^{R}$ \\
\hline Erythromycin & 15 & $0 \pm 0^{R}$ \\
\hline Furazolidone & 30 & $17.75 \pm 1.06^{\mathrm{R}}$ \\
\hline Gentamycin & 10 & $20.20 \pm 0.28^{S}$ \\
\hline Kanamycin & 30 & $18.75 \pm 0.07^{\mathrm{s}}$ \\
\hline Neomycin* & 30 & $23.25 \pm 0.21^{\mathrm{s}}$ \\
\hline Norfloxacin & 10 & $0 \pm 0^{R}$ \\
\hline Ofloxacin & 5 & $0 \pm 0^{R}$ \\
\hline Penicillin & 10 & $0 \pm 0^{R}$ \\
\hline Streptomycin & 10 & $15.25 \pm 0.35^{\mathrm{s}}$ \\
\hline Sulfamethoxazole* & 300 & $0 \pm 0^{R}$ \\
\hline Sulfamethoxydiazine & 5 & $0 \pm 0^{R}$ \\
\hline Tetracycline & 30 & $21.00 \pm 1.41^{\mathrm{S}}$ \\
\hline
\end{tabular}

Data are presented as the mean \pm standard deviation

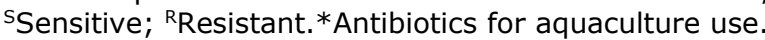

\section{Discussion}

S. maltophilia in aquaculture has been documented and associated with mortality in African catfish Clarias gariepinus (Abraham et al., 2016), channel catfish Ictalurus punctatus (Geng et al., 2010), turbot Scophthalmus maximus (Wu et al., 2014). However, there is limited information on S. maltophilia as a causal agent for cultured yellow catfish. In this study, we characterized the phenotype, taxonomic position, and antibiotic susceptibility of S. maltophilia WY1. To our knowledge, this is the first report of a S. maltophilia pathogen as a causative agent for ascites in farmed yellow catfish. 
S. maltophilia is considered a fish pathogen with the ability to produce enzymatic virulence factors such as protease, lipase, and hemolysin (Geng et al., 2006). Fish diseases caused by $S$. maltophilia are usually associated with the production of these virulent factors (Chen et al., 2008). In the present study, the WY1 isolate of S. maltophilia attained an LD50 mortality in healthy yellow catfish when challenged with a concentration of $1.12 \times 10^{5} \mathrm{CFU} / \mathrm{mL}$. This further demonstrates the potential threat of WY1 to yellow catfish farming. Apart from the virulence of the WY1 isolate, there might be other causes of ascites that should be raised as concerns, such as high density stocking, lack of food disinfection, high ammonia and nitrite levels in farming waters (Cao et al., 2013; Zhang et al., 2015).

Antibiotic resistance of $S$. maltophilia has developed due to massive use of antimicrobials for treatment of fish bacteriosis (Hu et al., 2015). Resistance to sulphamethoxazole is an indicator of multiple drug resistance (Zhao et al., 2017). In our study, the resistance to sulfamethoxazole is observed in the WY1 isolate, which is consistent with the fact of multiple resistance of isolate WY1. This is usually associated with the presence of sul and dfrA genes in integrons (Zhao et al., 2017). The resistance to penicillins and quinolone antibiotics is also noted in S. maltophilia isolated from $I$. punctatus (Geng et al., 2010). The WY1 isolate exhibited sensitivity to doxycycline and neomycin used in the fish farming regions, suggesting that the outbreak of this disease may not have resulted from the abuse of these antibiotics.

In conclusion, the present study for the first time reports a S. maltophilia isolate as a pathogen for cultured yellow catfish. The pathogenicity of the WY1 isolate supports this infection as an emerging threat in yellow catfish farming.

\section{Acknowledgments}

This work has been financially supported by the Earmarked Fund for Fishery Sci-Tech Innovation \& Popularization Project of Jiangsu Province (No. Y2017-6), Earmarked Fund for China Modern Shrimp Industry Technology Research (No. nycytx-46), Minhang District Industry-University-Research Institute Program, Shanghai (No. 2016MH252) and Special Fund for Agro-scientific Research in the Public Interest (No. 201503108-CC-1, 201203085).

\section{References}

Abraham T.J., Paul P., Adikesavalu H., Patra A., Banerjee S., 2016. Stenotrophomonas maltophilia as an opportunistic pathogen in cultured African catfish Clarias gariepinus (Burchell, 1822). Aquaculture, 450(1):168-172.

Cao H., Zheng W., He S., Ye X., Xiao G., Yang X., 2013. Identification of a Vibrio cholerae isolate as the causal agent of ascites disease in cultured mandarin fish Siniperca chuatsi (Basilewsky). Israeli Journal of Aquaculture-Bamidgeh, IJA_65.2013.914.

Chen D., Wang K., Geng Y., Huang X., 2008. Biological characteristics and pathogenicity of extracellular products of Stenotrophomonas maltophilia from channel catfish Ictalurus punctatus. Reservoir Fisheries, 28(1): 99-101.

Cheng P., Zhang F., Li S., Guan X., Yang Z., 2013. Isolation, identification and drug sensitive test on pathogens of skin ulcer from European bream. Journal of Aquaculture, 34(10): 1-4.

Geng Y., Wang K., Chen D., Huang X., 2006. Progress on research of Stenotrophomonas maltophilia. Progress in Veterinary Medicine, 27(5): 28-31.

Geng Y., Wang K., Chen D., Huang X., He M., Yin Z., 2010. Stenotrophomonas maltophilia, an emerging opportunist pathogen for cultured channel catfish, Ictalurus punctatus, in China. Aquaculture, 308(3-4):132-135.

Hu L., Zhu S., Peng L., Xu F., Zhou Z., Cai Y., 2015. The harm and problem analysis of drug abuse in aquaculture. Chinese Journal of Fisheries, 28(2): 47-54.

Huang Y., Li X., Wu X., Pang Y., Huang G., Wei X., Tong G., 2010. Detection and diagnosis procedure for fish parasitic diseases. Fisheries Science \& Technology Information, 37(2):83-85.

Joseph N.M., Sistla S., Dutta T.K., Badhe A.S., Rasitha D., Parija S.C., 2011. Reliability of Kirby-Bauer disk diffusion method for detecting meropenem resistance 
among non-fermenting gram-negative bacilli. Indian Journal of Pathology \& Microbiology, 54(3): 556-560.

Li M., 2000. Artificial farming feasibility and practical technology of yellow catfish Pelteobagrus fulvidraco. Feed Research, 11:40-41.

Li Y., Yan X., Chen J., Wang Y., Li Q., 2006. Studies on the characteristics of pathogenic Edwardsiella tarda isolated from diseased Scophthalmus maximus. Periodical of Ocean University of China, 36(4): 649-654.

Ma J., Jiang N., Liu W., Zhou Y., Wen H., Zeng L., 2015. Preliminary observation of a viral agent by electron microscopy associated with an epizootic mortality in farmed tilapia. Freshwater Fisheries, 45(6):94-96.

Ministry of Agriculture of China, 2017. China Fishery Statistical Yearbook. Beijing: China Agriculture Press, 25 pp.

Nishimori E., Kita-Tsukamoto K., Wakabayashi H., 2000. Pseudomonas plecoglossicida sp. nov., the causative agent of bacterial hemorrhagic ascites of ayu, Plecoglossus altivelis. International Journal of Systematic and Evolutionary Microbiology, 50: 83-89.

Ogbuagu D.H., Iwuchukwu E.I., 2014. Evaluation of the toxicity of three hair shampoos on the catfish (Clarias gariepinus) fingerlings. Applied Ecology \& Environmental Sciences, 2(3): 86-89.

Wei C., Peng Y., Liu J., Hu D., Huang Y., Mi Q., Liang J., Huang J., 2014. Isolation and identification of ascites disease pathogen from channel catfish and its drug sensitivity test. Journal of Southern Agriculture, 45(5): 875-881.

Wu X., Bai D., Zhu G., Ji Y., Jia Z., Zhou P., 2014. Isolation, identification, antibacterial effects of antibiotic drugs, and Chinese herbal extracts to the pathogenic bacteria of swollen abdomen from Scophthalmus maximus in Vitro. In: Zhang T.C., Ouyang P., Kaplan S., Skarnes B. (eds) Proceedings of the 2012 International Conference on Applied Biotechnology (ICAB 2012). Lecture Notes in Electrical Engineering, vol. 250. Springer, Berlin, Heidelberg.

Yang Y., Guo C., Cao H., Lu L., Yang X., 2017. Shewanella putrefaciens: an emerging pathogen for farmed yellow catfish Pelteobagrus fulvidraco. Israeli Journal of AquacultureBamidgeh, IJA_69. 2017. 1425.

Zhang T., Song W., Fu L., Hu Z., Li H., Yan Y., 2015. Effects of conventional water quality factors on histopathology of yellow catfish (Pelteobagrus fulvidraco) with ascites. Chinese Journal of Fisheries, 28(3): 30-34.

Zhang T., Song W., Yu X., Zhao X., Fu L., Hu Z., Qi H., Li H., 2009. Histopathological study of ascites disease in Pseudobagrus fulvidrico. Chinese Journal Fisheries, 22(2): 2933.

Zhang X., Li Y.W., Mo Z.Q., Luo X.C., Sun H.Y., 2014. Outbreak of a novel disease associated with Vibrio mimicus infection in fresh water cultured yellow catfish, Pelteobagrus fulvidraco. Aquaculture, 432: 119-124.

Zhao S., Yang L., Liu H., Gao F., 2017. Stenotrophomonas maltophilia in a university hospital of traditional Chinese medicine: molecular epidemiology and antimicrobial resistance. Journal of Hospital Infection, 96(3): 286-289.

Zheng W., Cao H., Yang X., 2012. Grass carp (Ctenopharyngodon idellus) infected with multiple strains of Aeromonas hydrophila. African Journal of Microbiology Research, 6(21):4512-4520.

Zhu Z., Shi X., Zhang S., Jiang G., Xing Z., Zhao Y., Li Z., Wu P., 2006. The pathogenic bacteria of the ascites in Japanese flounder (Paralichthys olivaceus). Fisheries Science, 25(7): 325-329. 